\title{
The Effect of Static Blasting Materials on Coal Structure Changes and Methane Adsorption Characteristics
}

\author{
Xiao Cui, ${ }^{1,2}$ Jiayong Zhang $\mathbb{D}^{1,2}$ Liwen Guo $\mathbb{D}^{1,2}$ and Xuemin Gong $\mathbb{C}^{3}$ \\ ${ }^{1}$ College of Mining Engineering, North China University of Science and Technology, Tangshan, Hebei 063210, China \\ ${ }^{2}$ Mining Development and Safety Technology Key Lab of Hebei Province, Tangshan, Hebei 063210, China \\ ${ }^{3}$ College of Chemical Engineering, North China University of Science and Technology, Tangshan, Hebei 063210, China \\ Correspondence should be addressed to Jiayong Zhang; zjy815@ncst.edu.cn and Xuemin Gong; gongxm1212@163.com
}

Received 19 July 2020; Accepted 5 August 2020; Published 29 August 2020

Academic Editor: Fernando Lusquiños

Copyright ( $) 2020$ Xiao Cui et al. This is an open access article distributed under the Creative Commons Attribution License, which permits unrestricted use, distribution, and reproduction in any medium, provided the original work is properly cited.

\begin{abstract}
Methane in coal seam is always under the dynamic process of adsorption and desorption. It has been demonstrated that the static blasting technology is an effective way to extract methane from coal. Although it is of great significance to understand the role of static blasting materials on methane extraction, the change of methane during static blasting is not well understood due to limited research studies. In this paper, we took the reaction pressure and heat from the hydration of the static blasting materials as the main factors. Microstructure changes in the static blasting materials and coal were analyzed by scanning electron microscopy, gas chromatography, infrared spectroscopy, and mercury injection. Changes of methane adsorption and adsorption rate before and after the static blasting were also measured. Our results demonstrated that the static blasting materials entered the microcracks of the coal body and the porosity of the coal was increased by heat expansion, improving methane migration. During the blasting process, methane began to desorb from the coal and its adsorption content was decreased. In contrast, the adsorption of methane was increased after the reaction. However, methane adsorption rate is higher than that of raw coal, indicating that the adsorbed methane is easier to convert into free methane, which is conducive to emission. This is of great significance to methane extraction and the safety of mines.
\end{abstract}

\section{Introduction}

During China's whole coal production and development, safe production and methane control at coalbed are of most importance $[1,2]$. Methane explosions have caused most serious coal mining accidents [3]. Thus, an effective prevention and control on methane should be taken. Methane at coalbed is a hazard to both coal production and mineral deposition $[4,5]$. The storage of coalbed methane in China is the third largest one in the world $[6,7]$. If the methane can be safely and efficiently extracted from the coalbed [8], it will not only improve the safety of mining but also provide economical energy to the society.

Permeability of coalbed is the main parameter for methane extraction $[9,10]$. With the increase of mining depth, the permeability is sharply decreased and the extraction effect is poor even if the number of methane extraction boreholes is greatly increased. Many techniques have been used to improve the permeability [11], such as hydraulic fracturing [12], hydraulic punching [13], $\mathrm{CO}_{2}$ cracking [14], and presplitting blasting [15]. As the coal mining goes deeper, the content of methane has increased sharply [16]. Therefore, more strategies are needed to improve the efficiency of methane extraction so as to ensure the safety of coal mining [17].

Static blasting technology is an efficient, economic, and environmentally friendly method for methane extraction. It can increase the permeability. As shown in Figure 1, in the static blasting technology, the static blasting materials are hydrated with water to form crystals with large volume and generate expansion pressure under the constraint conditions. They fracture and slowly loosen the coal and rock mass. The fracture is formed when the coal body is moved [18-20], which further develops the fracture and forms the 


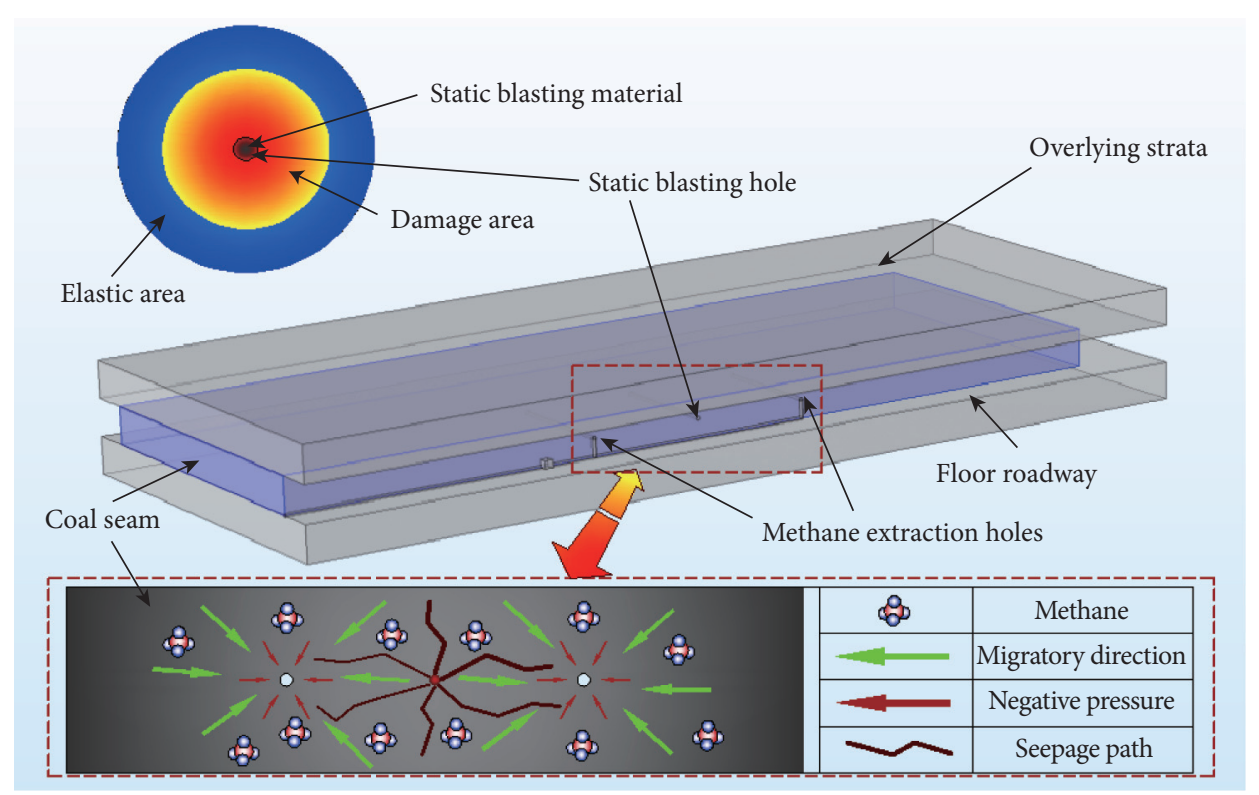

FIGURE 1: Mechanism of static blasting action during coalbed methane extraction.

methane release channel, thus improving the extraction efficiency of methane [21].

It should be noted that the effects of the static blasting materials on the physicochemical structure of coal and their thermal behavior have not been well investigated. There is still a lack of good understanding in terms of the role of the static blasting materials on the structure of coal and their consequent impact on methane adsorption. In this study, we measured the expansion pressure and hydration reaction temperature of static blasting materials, the main influencing indexes to coal structure and methane adsorption. Structure and physical changes of coal were determined by FTIR, mercury injection, and gas chromatography. The high-pressure capacity method was carried out to study methane adsorption behavior before and after the static blasting.

\section{Materials and Methods}

2.1. Materials. The static blasting materials were calcined at the temperature between 1350 and $1500^{\circ} \mathrm{C}$, and they were comprised of calcium oxide $(\mathrm{CaO})$, silicon dioxide $\left(\mathrm{SiO}_{2}\right)$, aluminium oxide $\left(\mathrm{Al}_{2} \mathrm{O}_{3}\right)$, and ferric oxide $\left(\mathrm{Fe}_{2} \mathrm{O}_{3}\right)$, as shown in Table 1. After calcination, tricalcium silicate $\left(\mathrm{C}_{3} \mathrm{~S}\right)$, tetracalcium aluminoferrite $\left(\mathrm{C}_{4} \mathrm{AF}\right)$, tricalcium aluminate $\left(\mathrm{C}_{3} \mathrm{~A}\right)$, and $\mathrm{f}-\mathrm{CaO}$ were produced based on the mass balance of the chemical composition $[22,23]$.

2.2. Coal Sample. Coal samples from Kailuan mining area in China were used in this study. The approximate analysis and density of coal samples are shown in Table 2. Before the analysis, all coal samples were ground and the particle sizes $<0.05 \mathrm{~mm}, 0.20-0.25 \mathrm{~mm}$, and $>5 \mathrm{~mm}$ were selected based on the testing requirements.
2.3. Methods. In accordance with the "soundless cracking agent" (JC/T 506-2008), a resistance strain gauge-steel pipe pressure testing machine was used to test the expansion pressure [24]. The expansion pressure of expansive material was calculated by equation (1). A MIK210B temperature recorder and Pt-100 lead temperature sensor were used to measure the reaction temperature of the static blasting materials (Figure 2).

$$
P_{r}=E_{s} \cdot\left(K^{2}-1\right)\left[\frac{\varepsilon_{\theta}}{(2-v)}\right],
$$

where $P_{r}$ is expansion pressure, $\mathrm{MPa}$; $E_{s}$ is elastic modulus of steel tube $(2.060 \times 105 \mathrm{MPa}) ; K$ is the ratio of the outside diameter to the inside diameter of the steel tube, $\mathrm{mm} / \mathrm{mm} ; \varepsilon_{\theta}$ is the circumferential direction strain values of the steel tube; and $v$ is Poisson's ratio, 0.3 .

A JSM-IT100 scanning electron microscope was used to examine the microstructure of the hydrated blasting materials and the coal samples $[25,26]$. A KKS-5690A gas chromatograph was used to analyze gas from coal by the action of static blasting materials. In the tests, the gas produced from coal samples in the tank was injected through a sampler and carried by hydrogen into a dedicated column [27]. The adsorption force of gas components in the column was different between desorption and adsorption state. By rinsing the column with hydrogen, two states of gas components were repeatedly divided and separated for several times. They were then detected by the postcolumn detector and converted to electrical signals which were sent to the chromatographic data processing system for analysis [28].

For FTIR analysis, $1-3 \mathrm{mg}$ of the static blasting materials and coal samples before and after static blasting was mixed with $100-300 \mathrm{mg} \mathrm{KBr}$ in an agate mortar and ground to below $2.5 \mu \mathrm{m}$. The mixing powders were then placed into a spindle briquetting machine and pressurized $\left(5-10 \mathrm{t} / \mathrm{cm}^{2}\right)$ for 
TABLE 1: Static blasting material components.

\begin{tabular}{lccccccccc}
\hline & \multicolumn{9}{c}{ Chemical composition (\%) } \\
LOI (loss on ignition) & $\mathrm{SiO}_{2}$ & $\mathrm{Al}_{2} \mathrm{O}_{3}$ & $\mathrm{Fe}_{2} \mathrm{O}_{3}$ & $\mathrm{CaO}$ & $\mathrm{MgO}$ & $\mathrm{f}-\mathrm{CaO}$ & $\sum$ & Liter weight (g/L) \\
\hline 0.62 & 5.41 & 1.10 & 2.60 & 89.10 & 0.92 & 73.26 & 99.75 & 1320 \\
\hline
\end{tabular}

TABLE 2: Density and proximate analysis of coal sample.

\begin{tabular}{lc}
\hline Parameters & \\
\hline Proximate analysis & \\
Total moisture $\left(M_{\mathrm{t}} \%\right)$ & 2.7 \\
External moisture $\left(M_{\mathrm{f}} \%\right)$ & 1.0 \\
Inherent moisture $\left(M_{\mathrm{inh}} \%\right)$ & 1.7 \\
Ash content $\left(A_{\mathrm{d}} \%\right)$ & 15.12 \\
Volatility $\left(V_{\mathrm{d}} \%\right)$ & 31.03 \\
Total sulphur $\left(S_{\mathrm{t}, \mathrm{d}} \%\right)$ & 0.42 \\
Calorific value $\left(Q_{\mathrm{net}, \mathrm{ar}} \mathrm{MJ} / \mathrm{kg}\right)$ & 26.98 \\
\hline Density & \\
True relative density $\left(\mathrm{g} / \mathrm{cm}^{3}\right)$ & 1.46 \\
Apparent relative density $\left(\mathrm{g} / \mathrm{cm}^{3}\right)$ & 1.43 \\
\hline
\end{tabular}

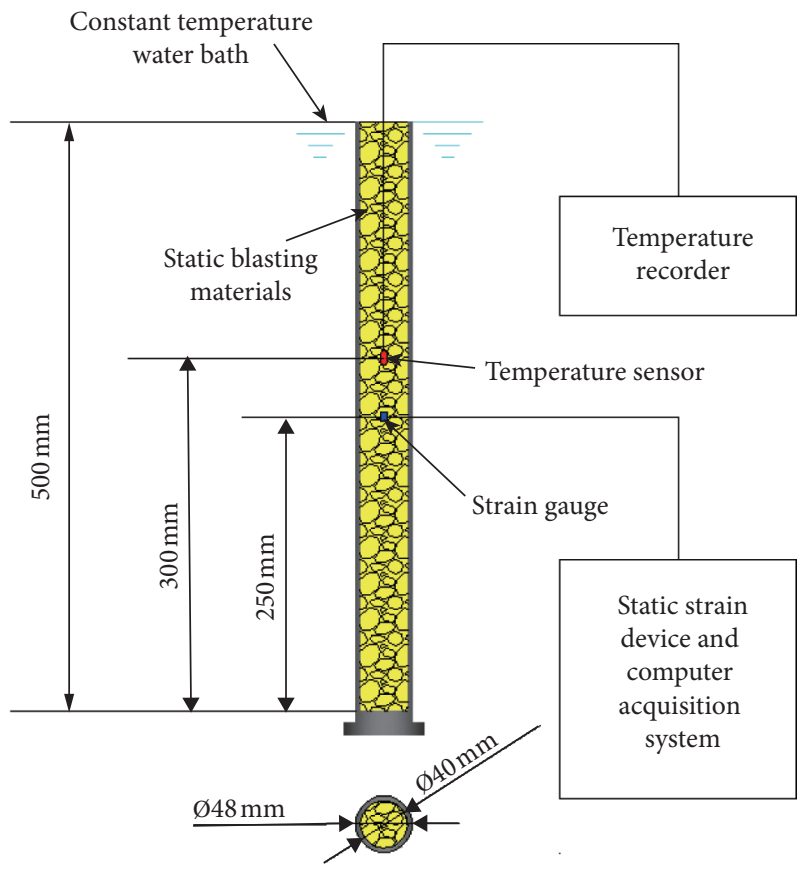

FIgURE 2: Measurement principle of reaction temperature and expansion pressure of static blasting materials.

about $5 \mathrm{~min}$ to obtain thin pastilles. An FTIR instrument (8400S) was used to record the spectra of the samples. Each spectrum was the result of signal-averaging of 10 scans at a resolution of $4 \mathrm{~cm}^{-1}$ and the scanning range was $4000-400 \mathrm{~cm}^{-1}$. For accuracy, the baseline correction was performed and normalized before the sample scan. Curvefitting was used to analyze the experimental data $[29,30]$.

Mercury injection tests were conducted to measure the distribution changes of microscopic pores in coal samples using a Micromeritics mercury porosimeter (AUTOPORE
IV 9500). In order to avoid the interference of water, the coal samples were fully dried in an oven under the vacuum and a constant temperature. The dimensions of the coal samples less than $15 \times 15 \times 15 \mathrm{~mm}$ were selected and put into the sample tube of the instrument. Mercury intrusion at pressures between $0.7 \mathrm{kPa}$ and $413.76 \mathrm{MPa}$, corresponding to the pore diameters ranging from 0.005 to $340 \mu \mathrm{m}$, was applied [31].

In order to study the pore changes of coal samples under the action of static blasting materials, a classification method for coal pore distribution reported by Hodott was adopted. It shows that the pore diameters of micropores, transition pores, mesopores, macropores, and visible pores and fissures correspond to the diameters of $<10 \mathrm{~nm}, 10-102 \mathrm{~nm}$, $102-103 \mathrm{~nm}, 103-105 \mathrm{~nm}$, and $>105 \mathrm{~nm}$, respectively. The volume of mercury in the pores under different pressures was calculated by Washburn equation (2). Cumulative distribution curve or differential curve corresponding to the pore size with different pressures was obtained [32].

$$
h^{2}=\operatorname{cr} \sigma \cos \theta t(2 \eta)^{-1}
$$

where $c$ is the capillary shape coefficient, $r$ is the average capillary radius, $\sigma$ is the surface tension of liquid, $\eta$ is liquid viscosity, and $h$ is the height of mercury at the different time point $t$. The relationship between the pore change and gas adsorption by the action of static blasting materials was determined.

There are three states of methane in coal: free, adsorbed, and absorbed methane [33]. The absorption of methane in coal body is too small to be determined. Free methane was calculated according to the coal porosity and methane pressure $[34,35]$. Methane adsorption capacity in coal body before and after static blasting was determined by the HAC-1 methane adsorption device using the high-pressure capacity method [36]. $0.2-0.25 \mathrm{~mm}$ of coal samples was selected. $50 \mathrm{~g}$ coal sample was carefully packed into the adsorption tank after drying and cooling. After the management information of the system software was set up, the adsorption test module was executed. The adsorption tank was placed in a super constant temperature water bath at $60^{\circ} \mathrm{C}$. When the vacuum of the degassing system reached less than $4 \mathrm{~Pa}$ and the degassing was continuous for $4 \mathrm{~h}$, the low-pressure adsorption test was conducted. After the lowpressure adsorption measurement, high-pressure methane was injected into the adsorption tank and the host was connected to the data acquisition instrument by the communication function test and analysis of the monitoring software. The high-pressure adsorption balance monitoring interface at the software was entered and the high-pressure adsorption tests were conducted. At the 


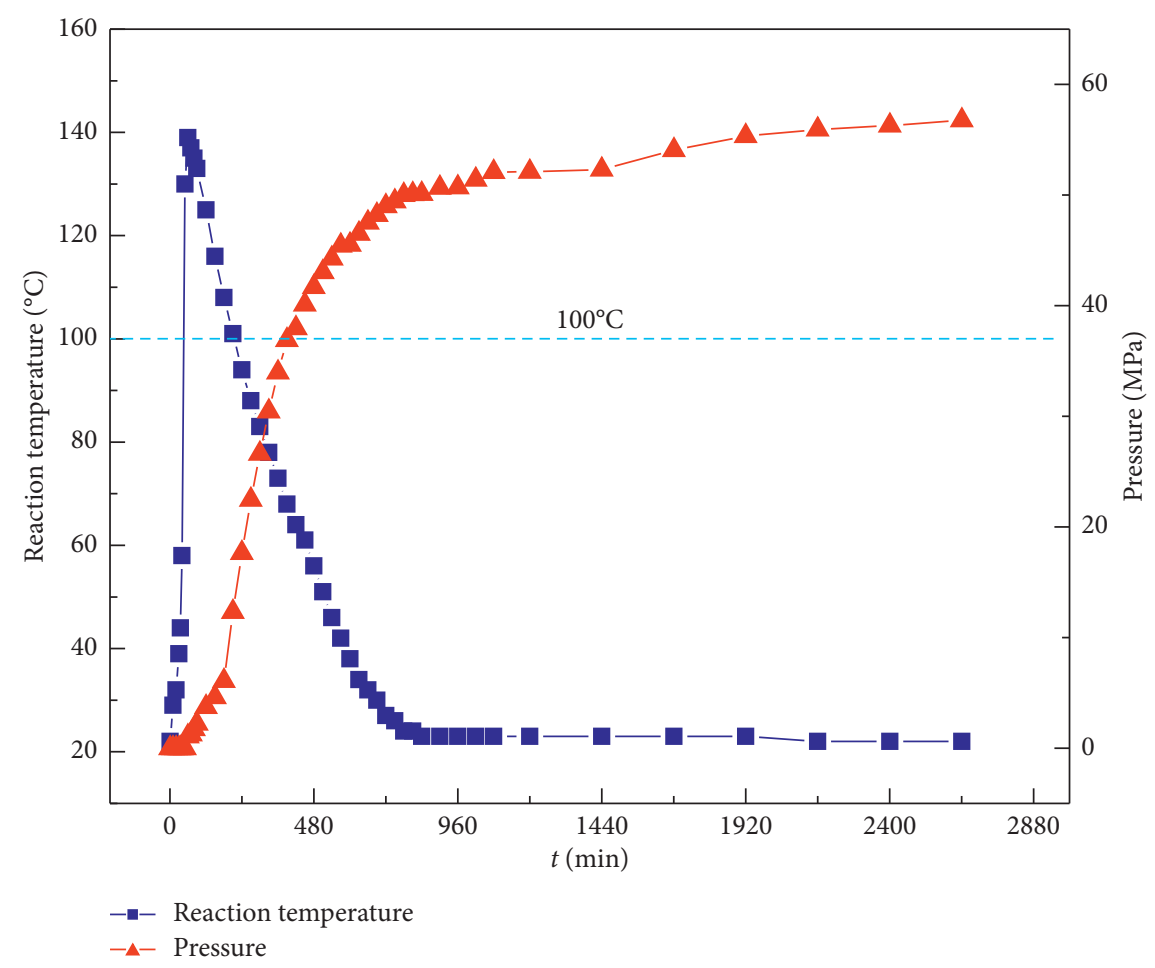

FIgURE 3: Temperature and expansion pressure during static blasting.

same time, the methane adsorption capacity and its adsorption rate on coal body at each pressure point were also recorded.

\section{Results and Discussion}

3.1. Testing of Reaction Parameters. Due to the complex geological environment and the unstable state of methane in coalbed, the reaction parameters of static blasting materials must be strictly controlled. In this study, the reaction temperature and expansion pressure, the most important parameters, were recorded. With the increase of the reaction temperature, the reaction rate was also increased. However, fast reaction rate resulted that the generated heat rapidly accumulates and cannot be released in a short time. As shown in Figure 3, during hydration of the static blasting materials, heat was released and the maximum reaction temperature reached to $140^{\circ} \mathrm{C}$. High expansion pressure ensures the fracture of coal seam. Our experimental results showed that the maximum pressure after hydration reaction was above $50 \mathrm{MPa}$ (Figure 3).

3.2. Microstructures of Static Blasting Materials and Coal Samples. SEM micrographs of the static blasting materials before and after hydration are shown in Figure 4. As can be seen, hydration obviously changed the microstructure and density of the blasting material. As shown in Figure 4(a), the static blasting materials before hydration were composed of particles with smooth, dense, and nonporous surfaces. Their apparent density was relatively high. The main component of the static blasting material is calcium oxide. Small and well dispersed particles favored hydration, resulting in the formation of calcium hydroxide crystal center and a large number of fine crystals. Figure 4(b) shows that the particles have a relatively rough surface with divergent microcracks and nanocracks. After hydration, many small voids were created. These particles were twice as large as that of the original ones and the porosity was also increased. These results indicated that hydration changed the morphology of the static blasting materials significantly.

Figures 5(a)-5(c) show the microstructure of raw coal and coal after static blasting. The microstructure and density of $1^{\#}$ raw coal and $2^{\#}$ coal were obviously different. The pore of $2^{\#}$ was increased significantly and its surface became smooth. Hydration products of the static blasting materials on $3^{\#}$ coal body were adsorbed on the pores of the coal. The static blasting material was mainly composed of massive layered crystals, and they were converted directly into a fine solid state after hydration, forming a gel and releasing heat. These gel-like particles were closely packed by condensation, and there were clear signs for their further crystallization and hardening.

3.3. Gas Chromatographic Analysis. Thermal decomposition and oxidation of coal were caused by the heat release during hydration of the static blasting materials. Gas products of coal were mainly $\mathrm{CO}, \mathrm{CH}_{4}, \mathrm{C}_{2} \mathrm{H}_{6}$, and $\mathrm{C}_{2} \mathrm{H}_{4}$. Figure 6 shows the content changes of gaseous products as a function of the reaction temperature. $\mathrm{N}_{2}$ concentration was slowly increased with the temperature but $\mathrm{O}_{2}$ was decreased, indicating the occurrence of coal-oxygen recombination reaction. When 


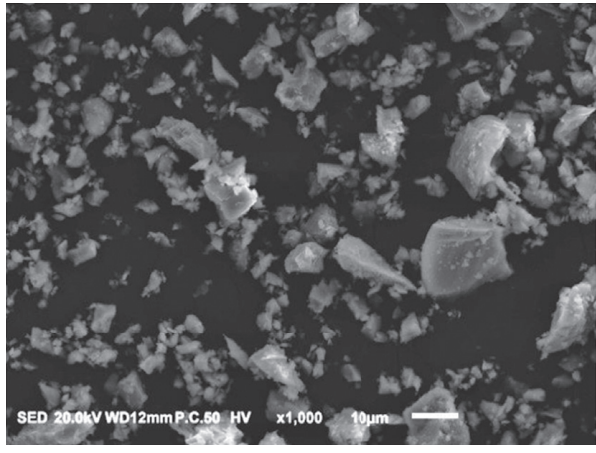

(a)

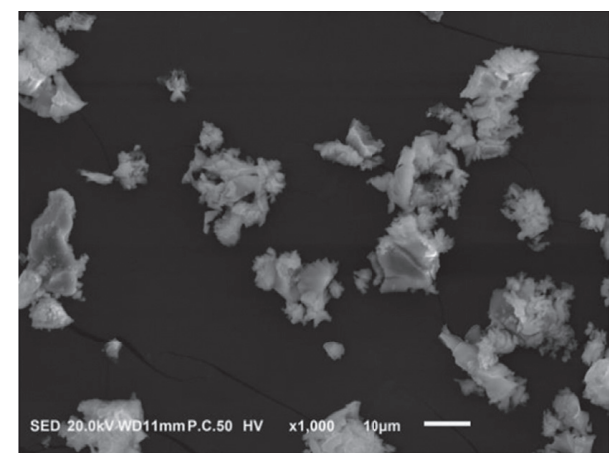

(b)

FIGURE 4: SEM micrographs of static blasting materials before and after hydration reaction: (a) before reaction; (b) after 24 hours of reaction.

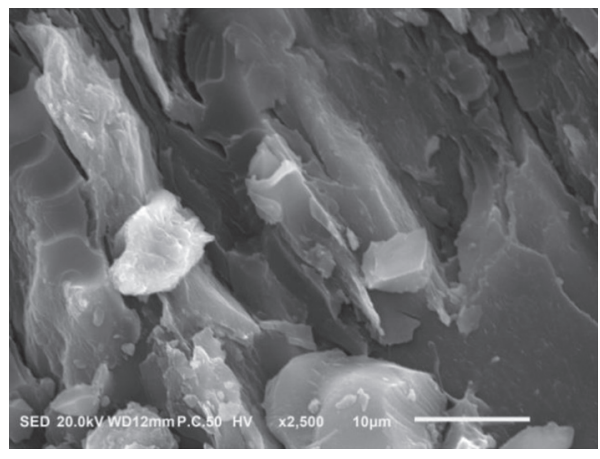

(a)

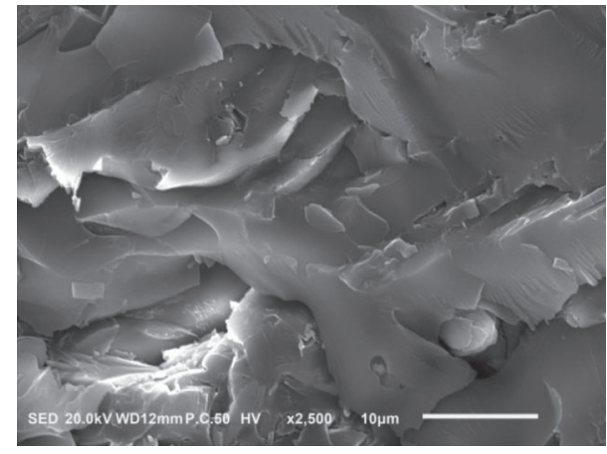

(b)

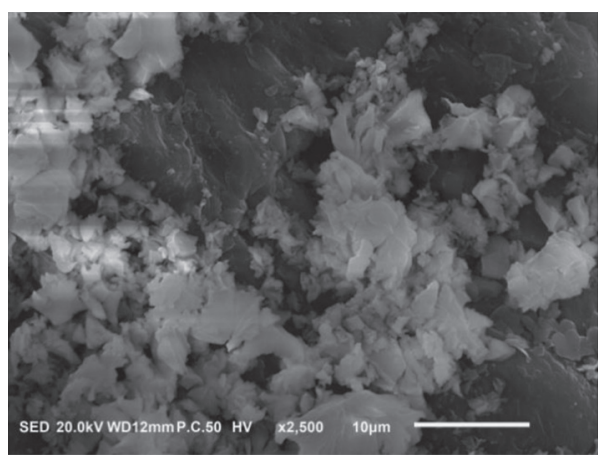

(c)

FIGURE 5: SEM micrographs of coal affected by static blasting: (a) $1^{\#}$ raw coal; (b) $2^{\#}$ coal after thermal action of the static blasting material; (c) $3^{\#}$ coal adsorbed by the static blasting material.

the reaction temperature reached $70^{\circ} \mathrm{C}, \mathrm{CO}$ began to be generated. Its concentration was then increased exponentially. At $150^{\circ} \mathrm{C}, \mathrm{O}_{2}$ was dropped sharply, suggesting the spontaneous combustion of coal entered in a critical acceleration stage. There was only a small amount of $\mathrm{CH}_{4}$ and $\mathrm{C}_{2} \mathrm{H}_{6}$ in the pores of the coal body. At $120^{\circ} \mathrm{C}$, the coal released $\mathrm{CH}_{4}$ and $\mathrm{C}_{2} \mathrm{H}_{6}$, indicating the increased pores and channels in the coal body. $\mathrm{C}_{2} \mathrm{H}_{4}$ began to appear at $140^{\circ} \mathrm{C}$, indicating that side chains and bridge bonds in the internal structure of coal began to break. Thus, $\mathrm{C}_{2} \mathrm{H}_{4}$ can be used as a marker to determine the pyrolysis and fission stage of coal during the static blasting process. The above results indicate that a very small amount of gas was generated in the static blasting process. The properties of the coal were not changed except its microstructure.

\subsection{FTIR Analysis}

3.4.1. FTIR Study of the Static Blasting Material. FTIR spectra of the static blasting material before and after reaction are given in Figure 7, together with the band assignment to their main functional groups. As shown in Figure $7(\mathrm{a})$, its IR spectra had a vibration frequency at 


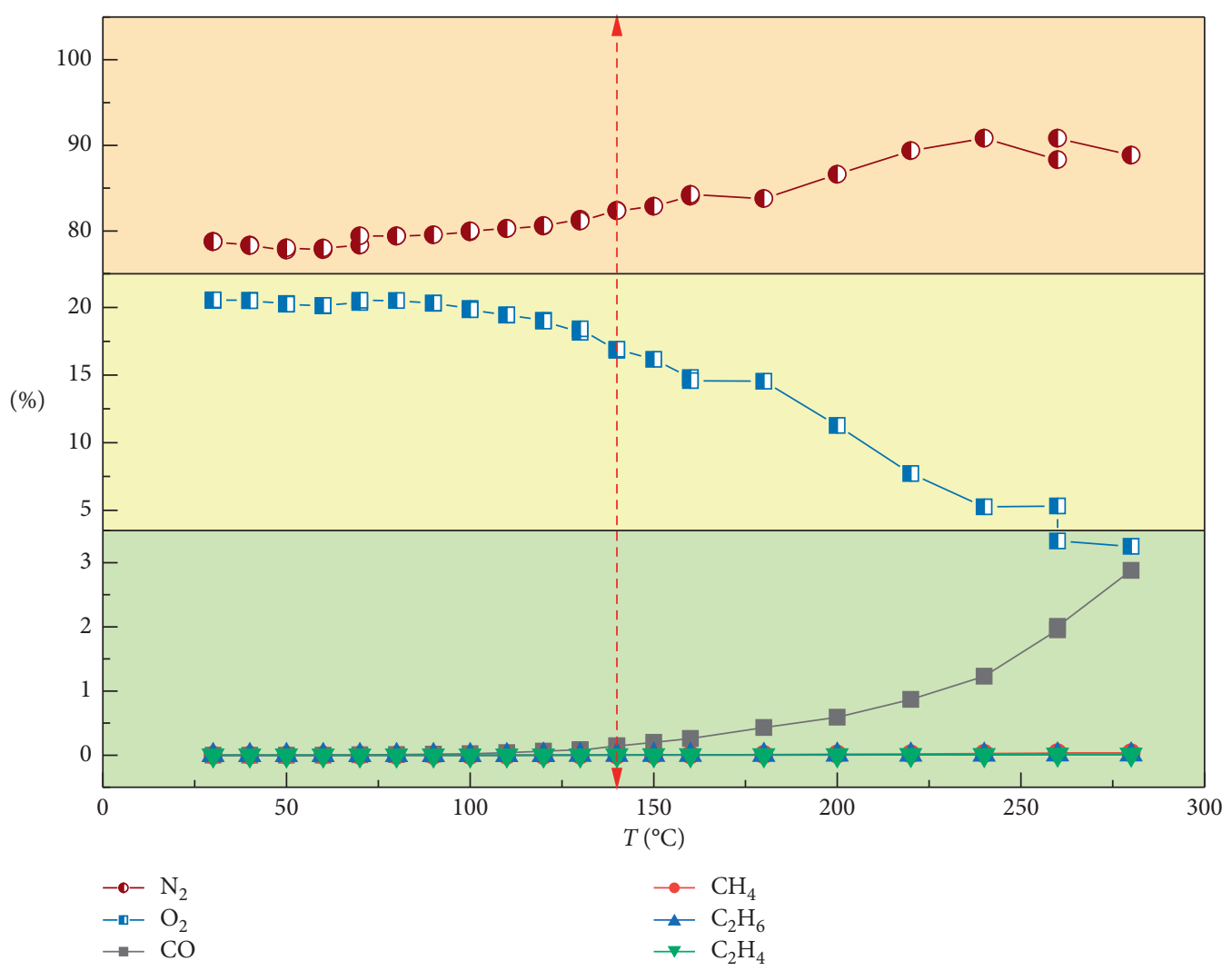

Figure 6: Gas chromatographic analysis of the coal samples under static blasting.

$3640 \mathrm{~cm}^{-1}$, representing the metal hydroxide $(-\mathrm{OH})$. In addition, a vibration frequency was observed at $2350 \mathrm{~cm}^{-1}$, representing carbon dioxide $\left(\mathrm{CO}_{2}\right)$. As shown in Figure $7(\mathrm{~b})$, the static blasting material after reaction presented a significant increment of peak intensity at $3640 \mathrm{~cm}^{-1}$ and $2350 \mathrm{~cm}^{-1}$. A vibration frequency at $1450 \mathrm{~cm}^{-1}$ was observed, indicating the formation of calcium carbonate. These results indicated that hydration of the static blasting material resulted in the formation of calcium hydroxide. Part of calcium hydroxide further reacted with carbon dioxide to form a small amount of calcium carbonate.

3.4.2. FTIR Analysis of the Coal Samples. Functional groups of coal before and after static blasting were also studied by FTIR (Figure 8). Coal is composed of a large number of aliphatic, aromatic, hydroxyl, and oxygen-containing functional groups. There are two obvious peaks at $2850 \mathrm{~cm}^{-1}$ and $2920 \mathrm{~cm}^{-1}$, which are from the symmetric and asymmetric stretching vibration of $\mathrm{CH}_{2}$ of coal, respectively. These $(\mathrm{C}-\mathrm{H})$ are from the aliphatic chain and saturated aliphatic ring. The peak near $1620 \mathrm{~cm}^{-1}$ is attributed to the antisymmetric stretching vibration of the carbonyl group (COO). $1440 \mathrm{~cm}^{-1}$ is the in-plane bending vibration of the hydroxyl alcohol $(\mathrm{C}-\mathrm{OH})$. There are three distinct peaks at 870,815 and $750 \mathrm{~cm}^{-1}$, representing the out-of-plane bending vibration of the aromatic ring $(\mathrm{CH})$. In addition, the peak strength of the $\mathrm{CO}_{2}$ groups at $2359 \mathrm{~cm}^{-1}$ was decreased after reaction. It was very likely that calcium hydroxide in the static blasting material reacted with $\mathrm{CO}_{2}$ to generate calcium carbonate. It should be noted that the chemical change of the coal was much less than that of the static blasting material in the reaction process.

3.5. Pore Variation in the Coal Sample. Figure 9 shows the area changes of pores in coal sample and intrusive mercury volume by the action of static blasting materials. Mercury first enters the space between particles. With the increase of pressure, energy consumption is manifested by compression of the particles. When the pressure gets higher, the particles absorb more energy and get further compressed. Meanwhile, mercury infiltrates into capillary pores of the material matrix under high pressure.

The mercury penetration volume in coal sample after static blasting was greater than that of the raw coal sample, followed by (A) raw coal $<$ (B) coal after heat action $<$ (C) coal with the static blasting material after the heat of the action. The volume of large holes did not change under the action of static blasting materials, whereas the volume of micropores and transition pores was increased significantly. Accordingly, the total volume of pores was increased.

Figure 10 shows the pore size distribution of coal before and after the action of static blasting materials. It can be observed that the pore size of coal was changed by the action of the static blasting material significantly. Comparing the differential interference curves and the logarithmic differential interference curves, it can be concluded that the static blasting material did not change the pore size distribution of coal sample, but increased 


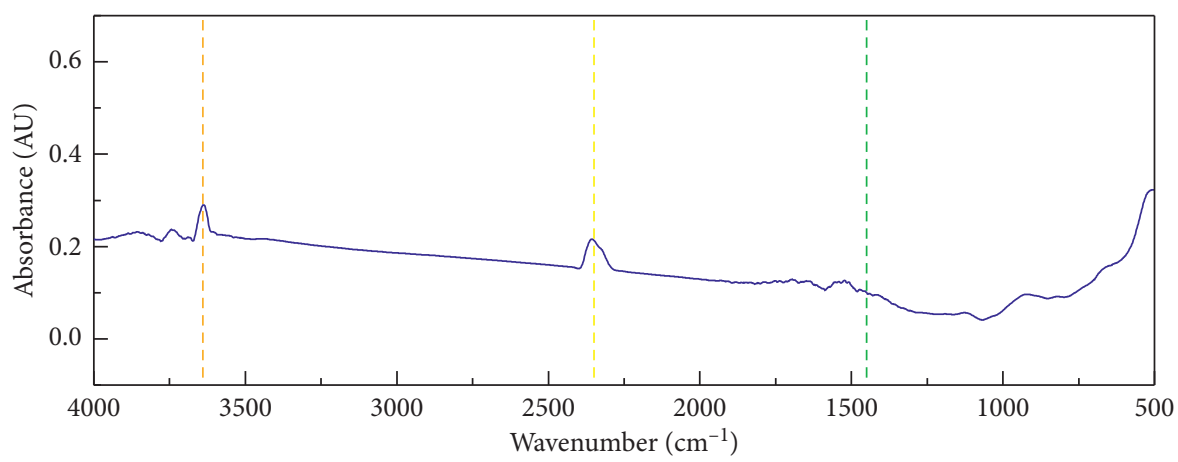

(a)

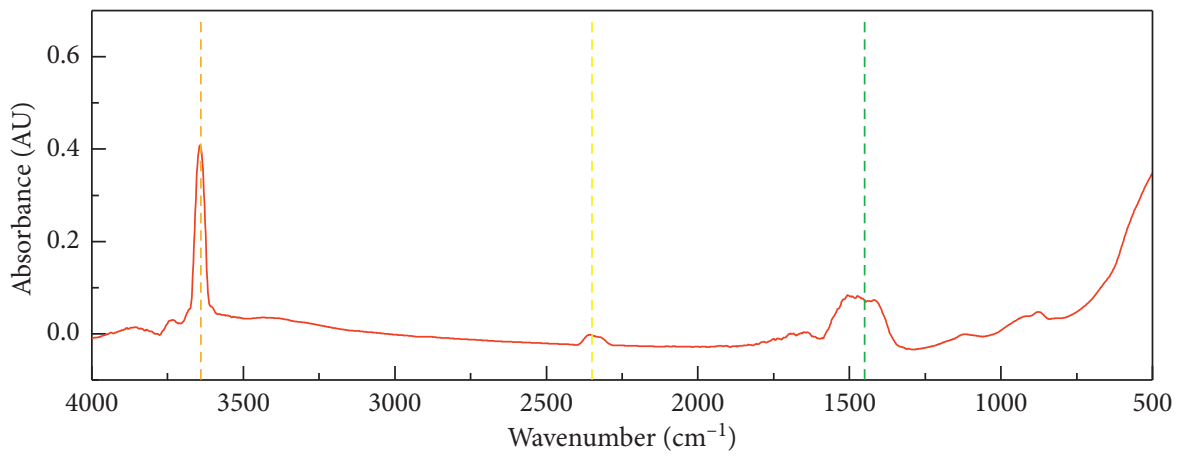

(b)

Figure 7: Gas chromatographic analysis of coal samples under static blasting.

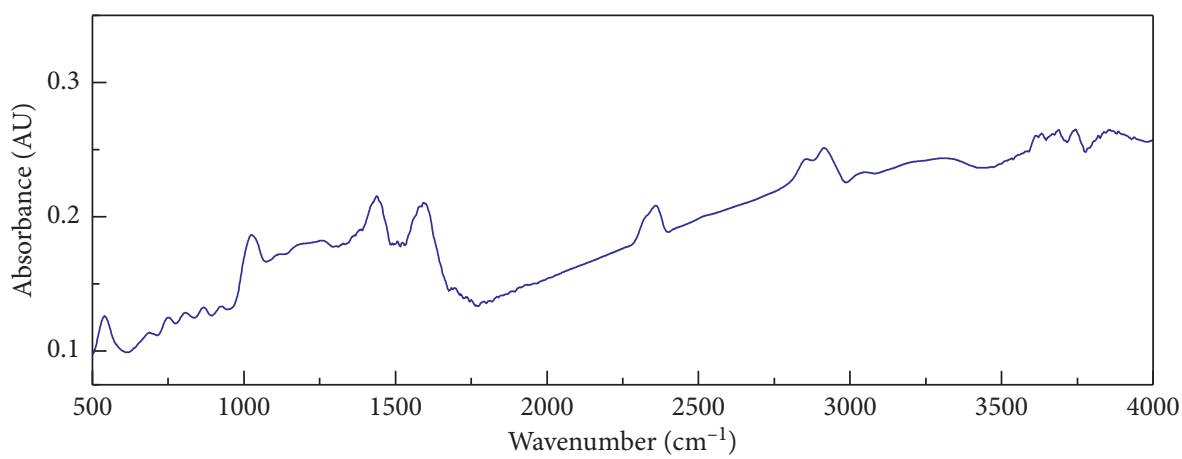

(a)

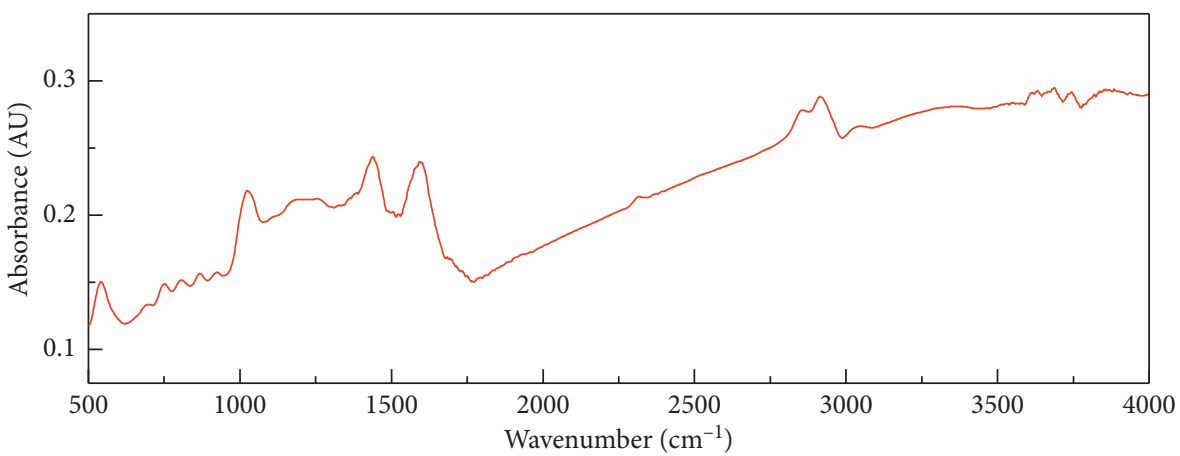

(b)

Figure 8: Infrared spectra of the coal samples before (a) and after (b) the action of static blasting materials. 


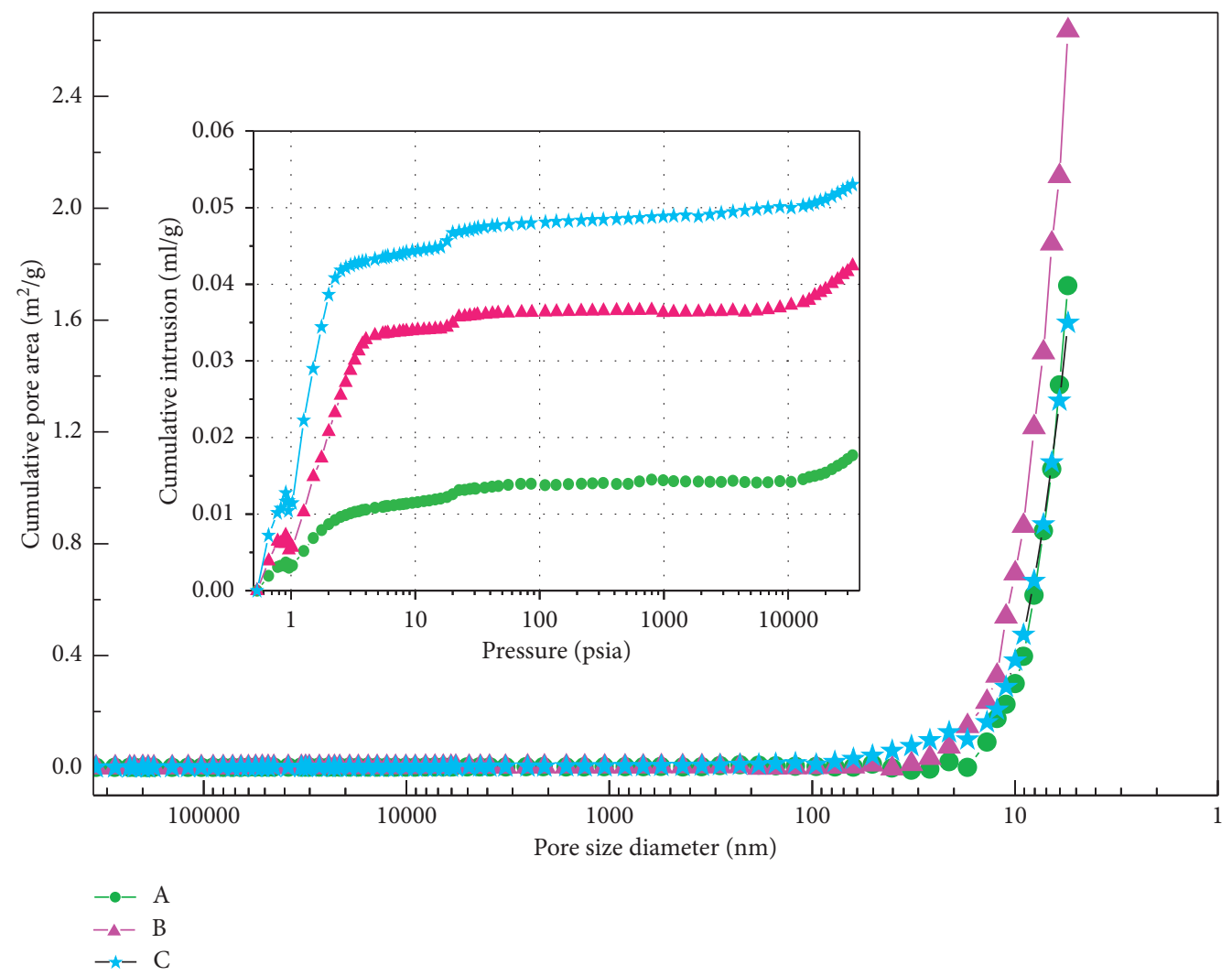

Figure 9: Cumulative pore area and intrusion mercury volume in coal samples: (A) raw coal, (B) coal after heat action, and (C) coal with static blasting material after heat action.

the visible pores and fissures. In addition, by comparing the measured results of mercury porosity in coal samples, it can be concluded that thermal action of the static blasting material has changed the distribution of main pores in coal samples. The static blasting material adsorbed on the coal samples resulted in the increase of the pore volume of the coal.

\subsection{Changes in Methane Adsorption}

3.6.1. Determination of Methane Adsorption. Changes of methane adsorption on coal samples during the whole process of static blasting were determined by the HAC-1 high-pressure capacity method. The methane adsorption curve under $0-5 \mathrm{MPa}$ was fitted by Langmuir function, and the results are presented in Figure 11. The effect of static blasting materials on coal samples is mainly reflected in two aspects. On the one hand, the static blasting materials attach to the coal body and are hydrated. On the other hand, the hydration reaction is exothermic, thus affecting the coal sample by heat expansion. As shown in Figure 11, methane adsorption on both the coal sample attached with the static blasting material and the coal sample heat treated by hydration was decreased significantly during the reaction process, indicating that the exothermic reaction is conducive to methane desorption and converting to free gas. After the reaction, the methane adsorption on the coal samples in both states was greater than that of the raw coal samples, indicating that the structure of the coal samples has been changed and this process is irreversible.

3.6.2. Rate of Methane Adsorption. Adsorption content and rate of methane on coal samples in each static blasting process are shown in Figures 12(a)-12(c), which showed that the adsorption rate of $2^{\#}$, the coal sample attached with the static blasting materials, was similar to that of $1^{\#}$, the raw coal sample. The only heated coal sample $3^{\#}$ is much lower than that of $1^{\#}$ raw coal sample. However, the adsorption content in $2^{\#}$ and $3^{\#}$ was smaller than that of $1^{\#}$. These results suggest that the adsorption capacity of methane can be greatly reduced during the reaction of static blasting materials. At the same pressure, methane adsorption content and adsorption time were decreased.

As shown in Figures 12(d) and 12(e), methane content and adsorption rate of coal samples $4^{\#}$ and $5^{\#}$ after the reaction of static blasting materials were increased significantly, indicating that methane adsorption capacity on coal samples was stronger than that of raw coal samples. Under the same pressure, it is easier and faster for coal to absorb methane after the action of static blasting materials. According to the analysis of the coal samples before and after the action of the static blasting materials by FTIR, the characteristics and functional groups of the coal have not changed significantly. Therefore, the adsorption area in coal samples after the action of static blasting materials was 


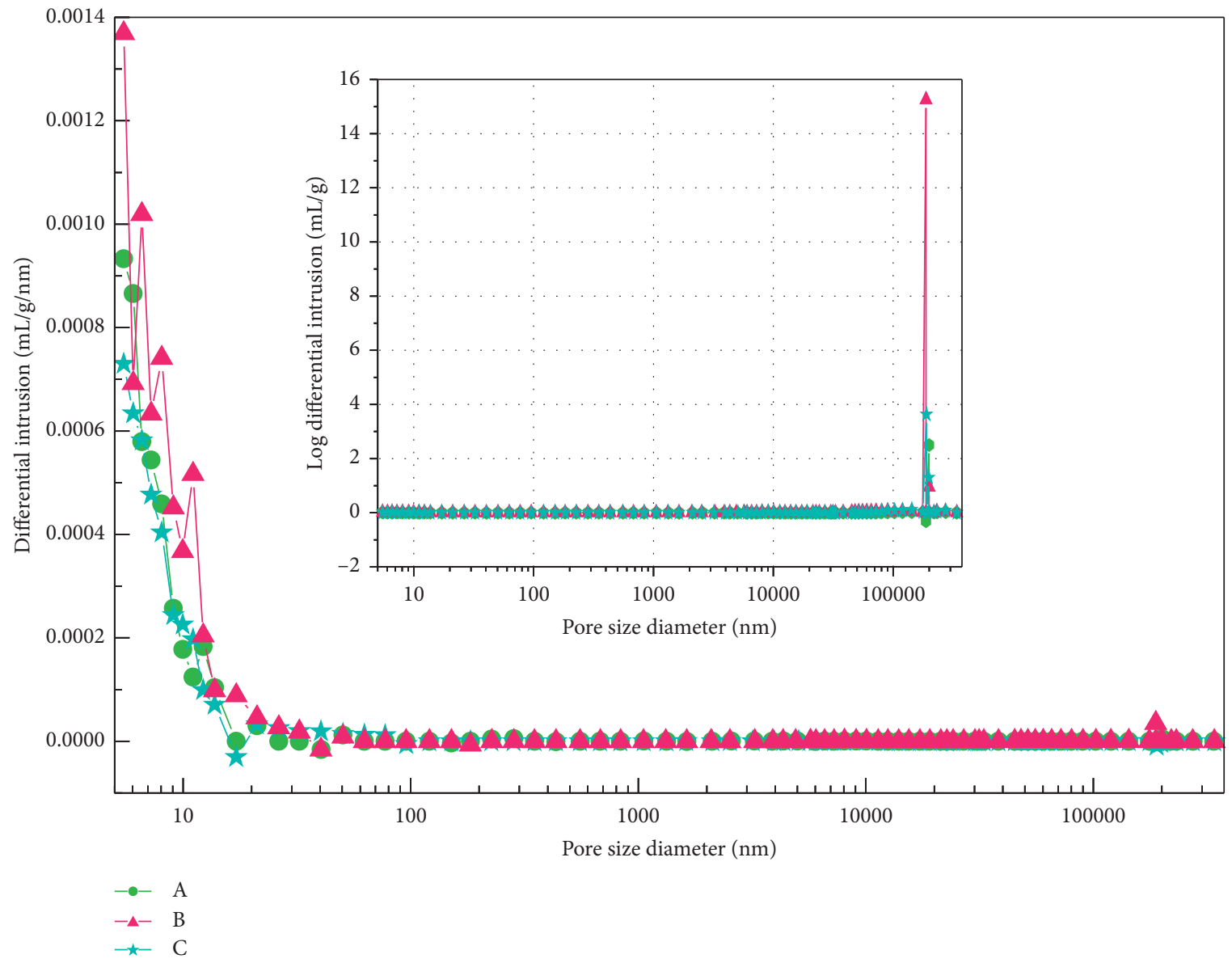

FIgURe 10: Differential intrusion and logarithmic differential intrusion of mercury in coal samples: (A) raw coal; (B) coal after heat action; (C) coal with static blasting material after heat action.

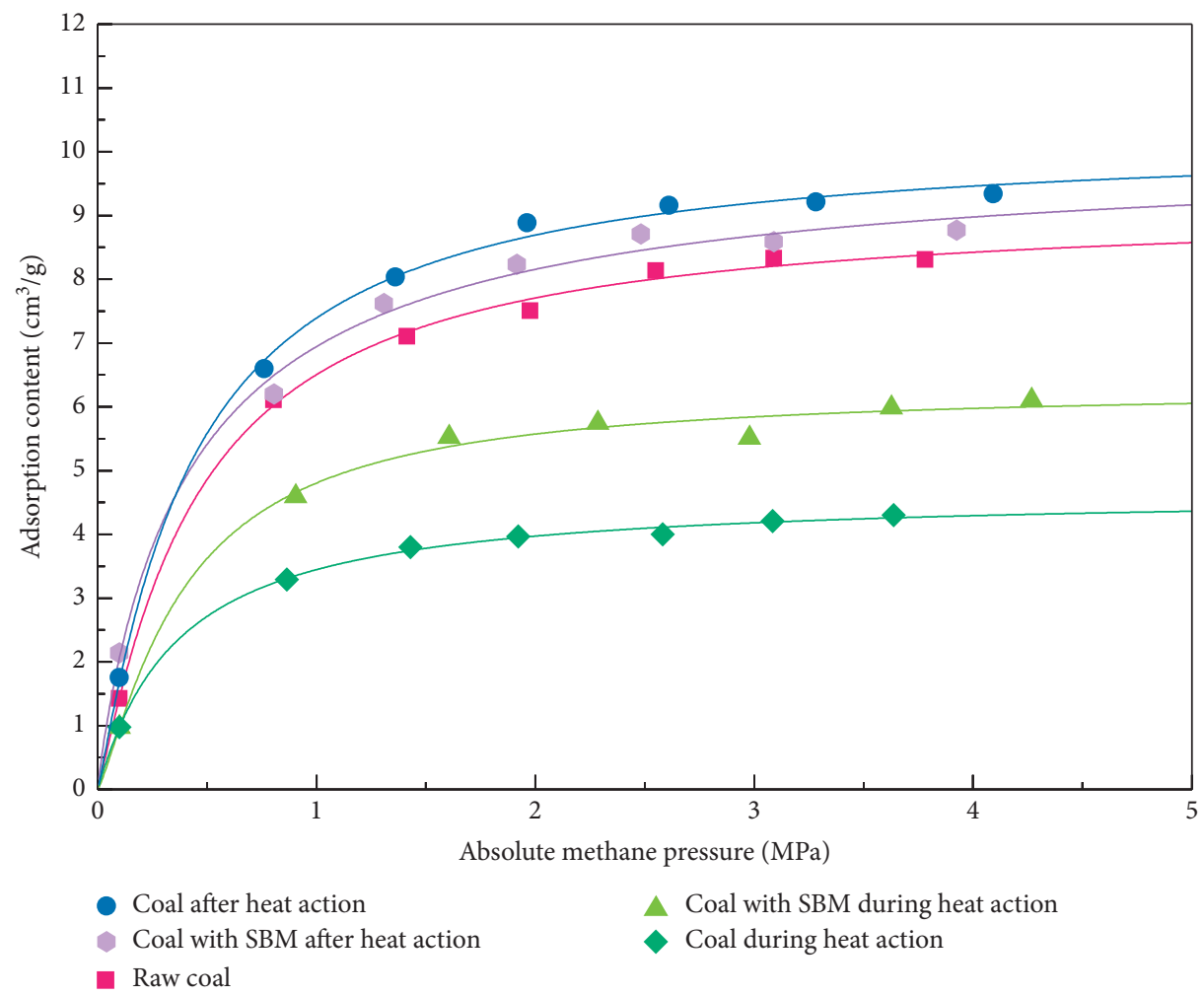

FIGURE 11: Methane adsorption curve of coal under static blasting material (SBM). 


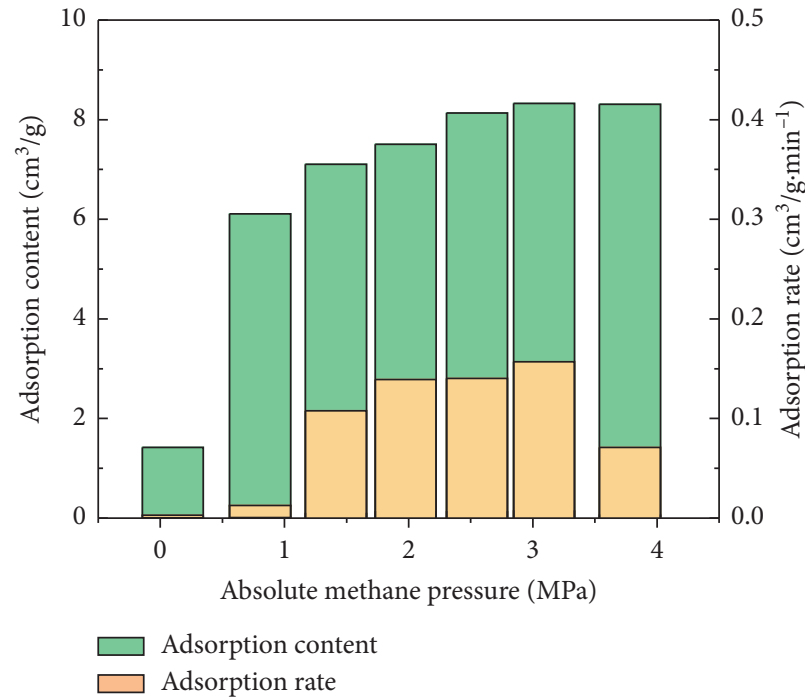

(a)

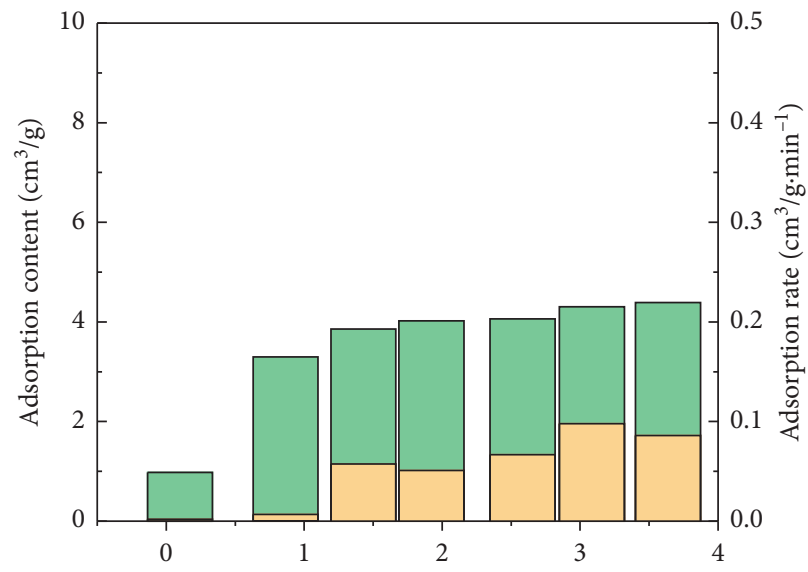

Absolute methane pressure (MPa)

Adsorption content Adsorption rate

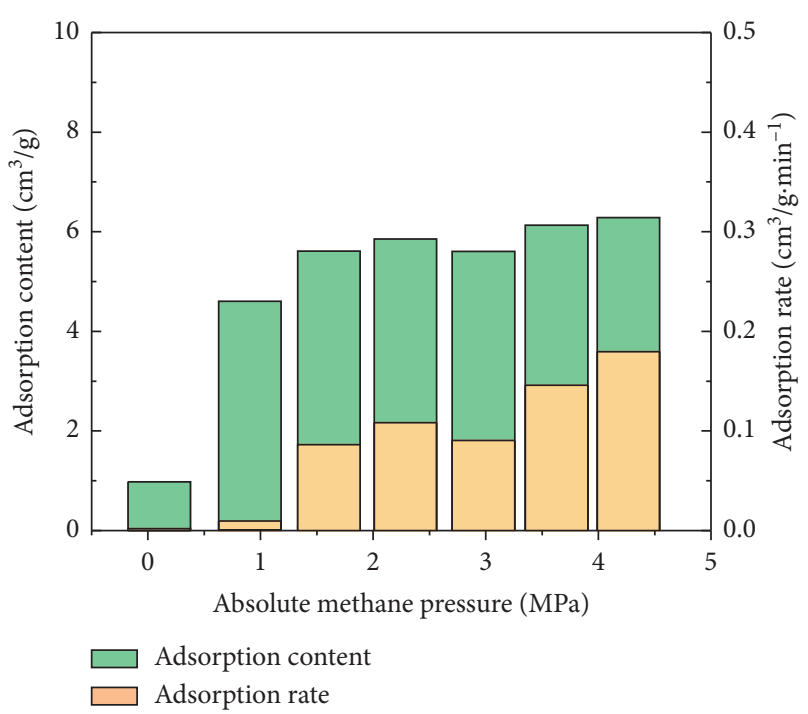

(b)

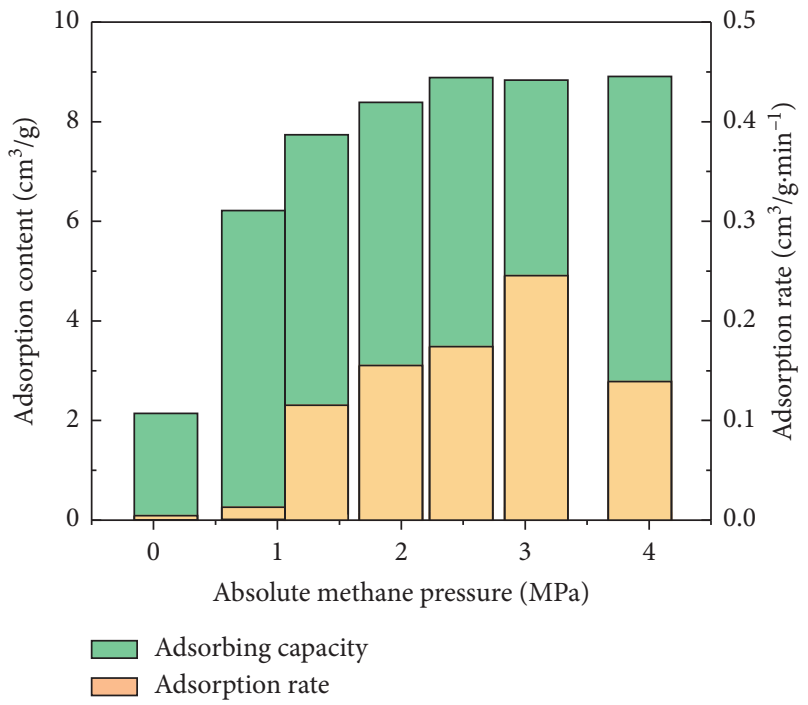

(d)

(c)

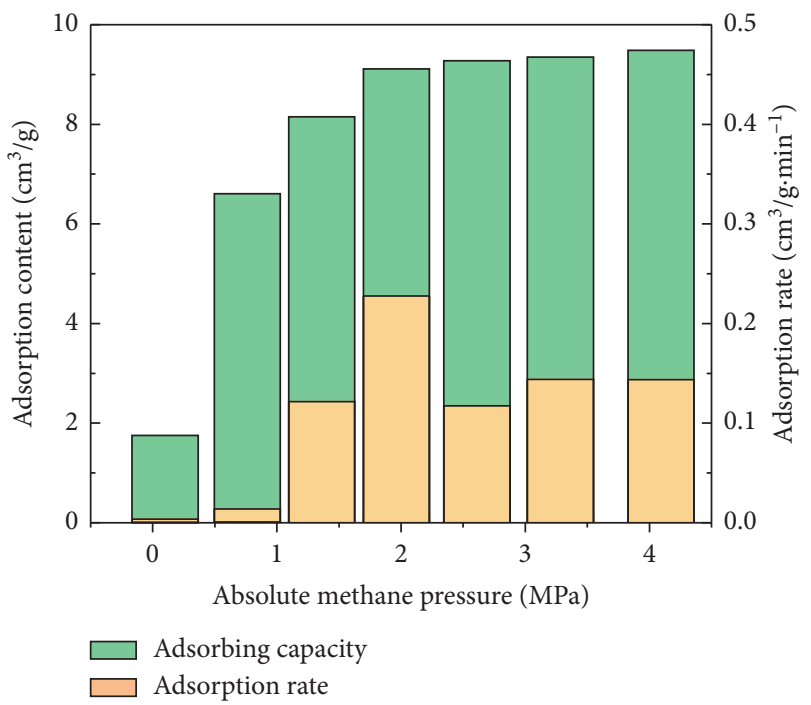

(e)

FigURE 12: Relationship between methane adsorption content and rate: (a) $1^{\#}$ raw coal, (b) $2^{\#}$ coal with static blasting material during heat action, (c) $3^{\#}$ coal during heat action, (d) $4^{\#}$ coal with static blasting materials after heat action, and (e) $5^{\#}$ coal after heat action. 
changed. The porosity and specific surface area of coal samples were increased, favored to methane adsorption. Although the adsorption capacity of methane to coal was enhanced, the adsorption state of methane was unstable and it was easy to extract methane in the case of negative pressure extraction.

\section{Conclusions}

Our results demonstrated that the maximum pressure after hydration reaction of static blasting materials was above $50 \mathrm{MPa}$, high enough to crush the coal macroscopically. During hydration of the static blasting material, a lot of heat was generated, resulting in the increase of the reaction temperature up to $140^{\circ} \mathrm{C}$ and mechanical changes of the coal. In addition, the main composition of the static blasting material is calcium oxide $(\mathrm{CaO})$ with crystal size of $0.3-20 \mu \mathrm{m}$. They were adsorbed to the coal and made microscopic effects on coal body.

Under the action of the static blasting material, the coal was pyrolyzed and oxidized, generating a very small amount of gas, such as $\mathrm{CO}, \mathrm{CO}_{2}, \mathrm{C}_{2} \mathrm{H}_{6}$, and $\mathrm{C}_{2} \mathrm{H}_{4}$. FTIR results confirmed that the main reaction products of static blasting materials were calcium hydroxide and a small amount of calcium carbonate. There was no significant change in the functional groups of the coal body, indicating that the static blasting material has little effect on the coal characteristics.

The results of mercury intrusion experiments showed that the surface area and pore volume of coal by the thermal action and adsorption of the static blasting material were increased. The porosity of the coal body was significantly improved, and the methane adsorption space was increased. Furthermore, the static blasting material attached to the pores of the coal body causes the coal attached to the static blasting material to have a smaller surface area than that of the coal subjected to the heat.

The methane adsorption experiment confirmed that the methane in coal was desorbed during the reaction of static blasting and the methane adsorption capacity was reduced. After the reaction, the methane adsorption capacity of the coal body was enhanced and the amount of adsorbed methane was higher than that of the raw coal. Methane adsorption capacity on coal body was followed by coal after heat action $>$ coal attached by static blasting materials after heat action $>$ raw coal $>$ coal attached by static blasting material during heat action $>$ coal during heat action. In addition, the rate of methane adsorption on the coal after the static blasting material action was higher than that of the raw coal, indicating that it is easier to adsorb methane. It also indicates that the pore space in the coal body is increased and the pore channel is open. Although the amount of methane adsorption in coal was increased, it was easier to extract gas from negative pressure in coal seams, which was beneficial to improving the efficiency of methane extraction.

\section{Data Availability}

The data used to support the findings of this study are available from the corresponding author upon request.

\section{Conflicts of Interest}

The authors declare that there are no conflicts of interest regarding the publication of this paper.

\section{Acknowledgments}

This research was supported by the National Natural Science Foundation Fund (51874012), the National Key Research and Development Plan (2018YFC0808100), the Hebei Natural Science Foundation Fund (E2016209249), and the Graduate Student Innovation Fund of North China University of Science Technology (2018B26).

\section{References}

[1] J. Zhang, D. Cliff, K. Xu, and G. You, "Focusing on the patterns and characteristics of extraordinarily severe gas explosion accidents in Chinese coal mines," Process Safety and Environmental Protection, vol. 117, pp. 390-398, 2018.

[2] S. Han, H. Chen, E. Stemn, and J. Owen, "Interactions between organisational roles and environmental hazards: the case of safety in the Chinese coal industry," Resources Policy, vol. 60, pp. 36-46, 2019.

[3] X. Meng, Q. Liu, X. Luo, and X. Zhou, "Risk assessment of the unsafe behaviours of humans in fatal gas explosion accidents in China's underground coal mines," Journal of Cleaner Production, vol. 210, pp. 970-976, 2019.

[4] L. D. Connell, M. Lu, and Z. Pan, "An analytical coal permeability model for tri-axial strain and stress conditions," International Journal of Coal Geology, vol. 84, no. 2, pp. 103-114, 2010

[5] T. A. Moore, "Coalbed methane: a review," International Journal of Coal Geology, vol. 101, pp. 36-81, 2012.

[6] D. Luo and Y. Dai, "Economic evaluation of coalbed methane production in China," Energy Policy, vol. 37, no. 10, pp. 3883-3889, 2009.

[7] H. Li, H. C. Lau, and S. Huang, "China's coalbed methane development: a review of the challenges and opportunities in subsurface and surface engineering," Journal of Petroleum Science and Engineering, vol. 166, pp. 621-635, 2018.

[8] C. Ö. Karacan, F. A. Ruiz, M. Cotè, and S. Phipps, "Coal mine methane: a review of capture and utilization practices with benefits to mining safety and to greenhouse gas reduction," International Journal of Coal Geology, vol. 86, no. 2-3, pp. 121-156, 2011.

[9] M. Mazzotti, R. Pini, and G. Storti, "Enhanced coalbed methane recovery," The Journal of Supercritical Fluids, vol. 47, no. 3, pp. 619-627, 2009.

[10] S. Zhang, J. Liu, M. Wei, and D. Elsworth, "Coal permeability maps under the influence of multiple coupled processes," International Journal of Coal Geology, vol. 187, pp. 71-82, 2018.

[11] F. Zhou, T. Xia, X. Wang, Y. Zhang, Y. Sun, and J. Liu, "Recent developments in coal mine methane extraction and utilization in China: a review," Journal of Natural Gas Science and Engineering, vol. 31, pp. 437-458, 2016.

[12] Z. He and B. Duan, "Significance of the dynamic stress perturbations induced by hydraulic fracturing," Journal of Petroleum Science and Engineering, vol. 174, pp. 169-176, 2019.

[13] Y. Zhao, B. Lin, T. Liu, Q. Li, and J. Kong, "Gas flow field evolution around hydraulic slotted borehole in anisotropic 
coal," Journal of Natural Gas Science and Engineering, vol. 58, pp. 189-200, 2018.

[14] H. Yan, J. Zhang, N. Zhou, and M. Li, "Staged numerical simulations of supercritical $\mathrm{CO}_{2}$ fracturing of coal seams based on the extended finite element method," Journal of Natural Gas Science and Engineering, vol. 65, pp. 275-283, 2019.

[15] Z. Wang, X. Chen, and S. Xing, "Study on stress field distribution characteristics under coal seam pre-splitting blasting," Procedia Engineering, vol. 84, pp. 913-919, 2014.

[16] W. Yang, B.-q. Lin, Y.-a. Qu et al., "Stress evolution with time and space during mining of a coal seam," International Journal of Rock Mechanics and Mining Sciences, vol. 48, no. 7, pp. 1145-1152, 2011.

[17] N. Vedachalam, S. Srinivasalu, G. Rajendran, G. A. Ramadass, and M. A. Atmanand, "Review of unconventional hydrocarbon resources in major energy consuming countries and efforts in realizing natural gas hydrates as a future source of energy," Journal of Natural Gas Science and Engineering, vol. 26, pp. 163-175, 2015.

[18] J. Zhang, X. Cui, D. Guo, J. Zhang, F. Li, and X. U. Shen, "Numerical simulation of spacing of gas drainage boreholes based on static fracturing," China Mining Magazine, vol. 26, no. 3, pp. 98-102, 2017.

[19] C. Zhai, J. Xu, S. Liu, and L. Qin, "Fracturing mechanism of coal-like rock specimens under the effect of non-explosive expansion," International Journal of Rock Mechanics and Mining Sciences, vol. 103, pp. 145-154, 2018.

[20] J. Xu, C. Zhai, L. Qin, and G. Yu, "Evaluation research of the fracturing capacity of non-explosive expansion material applied to coal-seam roof rock," International Journal of Rock Mechanics and Mining Sciences, vol. 94, pp. 103-111, 2017.

[21] C. Zhang, L. I. N. Bai-quan, Y. Zhou, C. Zhai, C. Zhou, and $\mathrm{X}$. Sun, "Deep-hole directional static cracking technique for pressure relief and permeability improvement in mining-coal bed," Journal of Mining \& Safety Engineering, vol. 4, pp. 600-604, 2013.

[22] S. Monosi, R. Troli, O. Favoni, and F. Tittarelli, "Effect of SRA on the expansive behaviour of mortars based on sulphoaluminate agent," Cement and Concrete Composites, vol. 33, no. 4, pp. 485-489, 2011.

[23] R. Sahamitmongkol and T. Kishi, "Tensile behavior of restrained expansive mortar and concrete," Cement and Concrete Composites, vol. 33, no. 1, pp. 131-141, 2011.

[24] China Building Materials Industry Standard, Soundless Cracking Agent (JC/T 506-2008), National Development and Reform Commission, Beijing, China, 2008, http://www. standardcnjc.com/index/standard/detail/id/138.html.

[25] B. Kwiecińska, S. Pusz, and B. J. Valentine, "Application of electron microscopy TEM and SEM for analysis of coals, organic-rich shales and carbonaceous matter," International Journal of Coal Geology, vol. 211, Article ID 103203, 2019.

[26] S.-B. Song, J.-F. Liu, D.-S. Yang et al., "Pore structure characterization and permeability prediction of coal samples based on SEM images," Journal of Natural Gas Science and Engineering, vol. 67, pp. 160-171, 2019.

[27] B. Zhou, S. Yang, C. Wang, J. Cai, Q. Xu, and N. Sang, "Experimental study on the influence of coal oxidation on coal and gas outburst during invasion of magmatic rocks into coal seams," Process Safety and Environmental Protection, vol. 124, pp. 213-222, 2019.

[28] Y. Mochizuki, Y. Ono, and N. Tsubouchi, "Evolution profile of gases during coal carbonization and relationship between their amounts and the fluidity or coke strength," Fuel, vol. 237, pp. 735-744, 2019.

[29] P. Paul, M. Starsinic, and M. Coleman, in Fourier Transform Infrared Spectra, J. R. Ferraro and L. J. Basile, Eds., Academic Press, Cambridge, MA, USA, pp. 169-241, 1985.

[30] J. Ibarra, E. Muñoz, and R. Moliner, "FTIR study of the evolution of coal structure during the coalification process," Organic Geochemistry, vol. 24, no. 6-7, pp. 725-735, 1996.

[31] C. Bergins, J. Hulston, K. Strauss, and A. L. Chaffee, "Mechanical/thermal dewatering of lignite. Part 3: physical properties and pore structure of MTE product coals," Fuel, vol. 86, no. 1-2, pp. 3-16, 2007.

[32] E. W. Washburn, "The dynamics of capillary flow," Physical Review, vol. 17, no. 3, pp. 273-283, 1921.

[33] Z. Wang, W. Su, X. Tang, and J. Wu, "Influence of water invasion on methane adsorption behavior in coal," International Journal of Coal Geology, vol. 197, pp. 74-83, 2018.

[34] P. Guo, Y. Cheng, K. Jin, and Y. Liu, "The impact of faults on the occurrence of coal bed methane in Renlou coal mine, Huaibei coalfield, China," Journal of Natural Gas Science and Engineering, vol. 17, pp. 151-158, 2014.

[35] Y. Yao, D. Liu, and S. Xie, "Quantitative characterization of methane adsorption on coal using a low-field NMR relaxation method," International Journal of Coal Geology, vol. 131, pp. 32-40, 2014.

[36] D. Zhao, C. Zhang, H. Chen, and Z. Feng, "Experimental study on gas desorption characteristics for different coal particle sizes and adsorption pressures under the action of pressured water and superheated steam," Journal of Petroleum Science and Engineering, vol. 179, pp. 948-957, 2019. 